\title{
Locomotor activating effects and addiction-like features of MDPV as assessed in preclinical studies: a review
}

\author{
JOSEP MORENO-RIUS \\ al189497@uji.es \\ DAVID PUBILL SÁNCHEZ \\ d.pubill@ub.edu \\ ELENA ESCUBEDO RAFA \\ eescubedo@ub.edu \\ JoRDI CAMARASA GARCIA \\ jcamarasa@ub.edu \\ MARTA MIQUEL \\ miquel@uji.es
}

\section{Resumen}

Introducción: La 3,4-Methylenedioxypyrovalerone (MDPV) es un componente de las denominadas sales de baño, aparecidas en el mercado a final de la década del 2000 debido a la falta de precursores de síntesis de MDMA, y su uso va en aumento. El objetivo de este trabajo es clarificar sus características farmacológicas y potencialidades adictivas. Método: Mediante búsquedas en PubMed, 21 estudios relacionados con la química, farmacología o potencial adictivo del MDPV fueron seleccionados. Resultados: El MDPV muestra ser capaz de inducir una potente hiperlocomoción, preferencias condicionadas, sensibilización conductual, autoadministración y altos puntos de corte en pruebas de razón progresiva. Conclusión: Los estudios revisados apuntan a que el MDPV es un potente psicoestimulante con un potencial adictivo similar al de la cocaína o la metanfetamina. Su abuso continuado podría llevar a una epidemia de adictos al MDPV.

Palabras clave: MDPV, sales de baño, preferencia condicionada, autoadministración, razón progresiva.

\section{Abstract}

Introduction: 3,4-Methylenedioxypyrovalerone (MDPV) is a major component of the new psychoactive substances termed "bath salts". These substances appeared on the drug market at the end of the last century given the lack of MDMA precursors, caused by its worldwide prosecution by governments and police agencies, and its growing use. The goal of this work was to clarify its pharmacological features and addiction-like potentialities. Methods: By PubMed searches, 21 studies related to MDPV chemistry, pharmaco- 
logy or addictive features were selected. Results: MDPV is seen to be able to induce potent hyperlocomotion, conditioned place preference, behavioural sensitisation, selfadministration and high breakpoints in progressive ratio schedules. Conclusion: The reviewed studies indicate that MDPV is a powerful psychostimulant with a similar addictive potential to that of cocaine or methamphetamine. Its abuse can lead to an epidemic of MDPV addicts.

Keywords: MDPV, bath salts, conditioned preference, self-administration, hyperlocomotion, progressive ratio.

\section{Introduction}

3,4-Methylenedioxypyrovalerone (1-(3,4-Methylenedioxyphenyl)-2-pyrrolidinylpentan-1one, MDPV) is a designer drug recently appeared on the market, normally sold as bath salts or fertilizers on the Internet (Penders and Gestring, 2011; Smith et al., 2011). Despite its recent appearance on the illegal drug market, this molecule, along with other analogues, was patented in 1969 by the German pharmaceutical company Boehringer Ingelheim as a centrally acting stimulant (de Felice et al., 2014) with potential as a possible treatment as narcolepsy and chronic fatigue. For this purpose came to market (Goldberg et al., 1973), but the abuse of it by addicts made it being withdrawn from circulation (Deniker et al., 1975). It is a synthetic derivative of cathinone, an amphetamine-like stimulant that has been used for thousands of years in Eastern Africa and in the Arabian countries (Kalix, 1992). From this molecule are derived the majority of drugs that comprise products sold as bath salts, among which we highlight, besides methylenedioxypyrovalerone, other substances such as mephedrone or methylone (Marusich et al., 2012). A tendency of increase in its consumption patterns as reflected by the data of seizures of this substance (UNODC, 2013). In addition, in some areas of Northern and Central Europe the consequences of its use are already beginning to suppose serious medical and social problems (Csáki et al., 2013; Simonsen et al., 2015). Therefore, our goal is to provide a brief explanation of MDPV's chemical properties and review the locomotor activating effects and addiction-like features of MDPV that have been assessed in preclinical studies, while comparing them with classic addictive drugs.

\section{Methods}

The following PubMed searches were performed: "MDPV AND chemistry", "MDPV AND locomotion", "MDPV AND preference", "MDPV AND self-administration" and "MDPV AND sensitization". After removing duplicates and critically revising all the search results, 21 studies were selected out of 129 potential results.

\section{Results}

The chemical properties of this drug are the following: Its name is (R/S) -1- (Benzo [d] $[1,3]$ dioxol-5-yl) -2- (pyrrolidin-1-yl) pentane-1-one; the molecular formula is, in the freebase 
form, $\mathrm{C}_{16} \mathrm{H}_{21} \mathrm{NO}_{3}$, it has a molecular weight of 275.35 grams per mol of MDPV and a melting point for the MDPV hydrochloride of between 238 and $239^{\circ} \mathrm{C}$ (Yohannan et al., 2010). Pure MDPV HCl is presented as a white crystalline powder. This form is highly soluble in water, but it also proves to be in methanol and chloroform. On the other hand, freebase MDPV is a non-crystalline powder which colors range from brown to yellow or green (Yohannan et al., 2010). The differences between MDPV isomers, which occurs due to the presence of a carbon atom that acts as a chiral center, there were no published data on this subject until recently. However, a very recent study conducted by Kolanos et al. (2015) addressed this issue. Reuptake inhibition of the dopamine transporter (DAT) assays showed an effect 10 times higher of S(+)MDPV on the other enantiomer. Additionally, an analysis of the facilitation of the intracranial self-stimulation thresholds shows that R(-)MDPV is unable to provide it, even at a dose 100 times superior to the minimum effective to facilitate the stimulation of $S(+) M D P V$. Such results indicate that neurochemical and possibly behavioral effects of racemic MDPV are strongly mediated by the $s(+)$ enantiomer.

In structural terms, this cathinone shares, in addition to the previously mentioned ketone group present in all cathinones, similarities with MDMA as it also owns a 3.4-methylenedioxy group, but is the presence of pyrrolidine group, together with the amino tertiary amino group which make this molecule less polar and highly lipophilic. Because of that, MDPV readily crosses the blood-brain barrier and it can exert their powerful psychoactive effects (Coppola and Mondola, 2012; Kolanos et al., 2013).

Regarding its in vivo pharmacological effects, it is well known that all addictive drugs, especially psychostimulants, have the ability of provoking hyperlocomotion by direct or indirect stimulation of the mesolimbic dopamine system (Wise and Bozarth, 1987). This property of MDPV has been quite extensively studied in recent years. As an example, the study conducted by Marusich et al. (2012) shows, using a functional observational battery, that MDPV produces, in mice, different types of stereotyped movements, such as circular, non-circular head movements and compulsive stereotyped movements. Another study in which MDPV-induced stereotypies are evaluated is the one from Aarde et al. (2013), who report that such stereotypies appeared when the drug was both yoked-administered and self-administered.

There are also a number of studies which assess MDPV-induced hyperlocomotion putting the animal in an open field where the horizontal distance traveled or the number of cut IR ray beams in a given period of time are counted. In this sense, the study by Aarde et al. (2013) shows that MDPV is able to induce locomotor activity in rats with similar potency to that of methamphetamine (METH) at doses of $0.5,1$ and $3.2 \mathrm{mg} / \mathrm{kg}$, but the $5.6 \mathrm{mg} / \mathrm{kg}$ MDPV dose caused greater hyperlocomotion than the same dose of METH.

In the aforementioned study by Marusich et al. (2012) hyperlocomotion induced by different doses of MDPV was also analyzed. All four doses (1,3, 10 and $17 \mathrm{mg} / \mathrm{kg})$ showed a significant increase locomotor activity. Also in this regard, Fantegrossi et al. (2013) also demonstrated a significant increase in activity, although this effect showed to be biphasic when the animal is placed at high room temperature $\left(28^{\circ} \mathrm{C}\right)$.

We can also highlight the study of Baumann et al. (2013), which compares the ability of MDPV and cocaine to induce locomotor activity in rats. The synthetic cathinone shows that a higher power than cocaine even at lower doses. These data are accompanied by microdialysis results that show MDPV is 10 times more potent than cocaine in increasing extracellular dopamine levels in the nucleus accumbens, a central part of the dopaminergic mesolimbic system on which all addictive drugs more or less directly act (Koob and Volkow, 2010).

We will discuss now the paradigms that have been traditionally used to study properties of addictive drugs, or other experiments that model some of the hallmarks of the addict. Also note that addiction, as of today, is considered a chronic and relapsing mental illness character- 
ized by compulsive drug seeking and taking that ends up in a loss of control over the amount of drug consumed. It is considered a mental disease because the continued use of the drug causes changes in brain function that can be long-lasting or even permanent (NIDA, 2014). Such changes are supposed to be, in turn, responsible for maintaining the pattern of compulsive drug seeking and taking characteristic of the addict. Of all models or tests used in the study of properties rewarding properties, conditioned preference procedures are arguably the most used ones. In these procedures, the experimental subject associates drug administration with a particular stimulus, by means of pairing of both of them repeatedly on alternate days. On the other days, saline administration is paired with a different stimulus. Once the drug administration cycle has been fulfilled the animal is tested, leaving him free access to both stimuli and recording the time spent with each one. A significant increase in the time the animal spends with the stimulus associated with the drug is interpreted as the substance administered during the previous phase is rewarding.

However, this inference is not uniquely accepted by the scientific community (Bardo and Bevins, 2000; Sanchis-Segura and Spanagel, 2006), and alternative interpretations have been proposed (Mead et al., 2005). Nevertheless, it is a fact that addictive drugs, in a certain dose range, have the ability to elicit this approach response towards the stimulus that have been paired with (Carbo-Gas et al., 2014; Braida et al., 2004). MDPV also shows this effect. There are two studies using this paradigm to evaluate these properties of this substance. One of them, led by King and colleagues in 2015 showed that the three tested doses $(1-3.2 \mathrm{mg} / \mathrm{kg}$ ) had the ability to elicit this response in rats. However, a not-so-recent study looks at the ability of different cathinones to set such preferences in mice, and were also compared to a classic addictive drug as amphetamine. Results show that MDPV was the only cathinone able to establish conditioned preference at all doses tested $(0.5-20 \mathrm{mg} / \mathrm{kg})$, while amphetamine was not able to elicit it in doses lower than $10 \mathrm{mg} / \mathrm{kg}$ (Karlsson et al., 2014).

Sensitization is a progressive increase of a drug effect caused by a repeated and intermittent drug administration. This theory suggests that the repeated exposure to a drug may cause a sensitization (hyperactivation) of the mesolimbic dopaminergic system. Such drug-induced sensitization makes drug users being more reactive to the drug and drug-associated stimuli. This system is responsible, in the authors' opinion, for attributing incentive or motivational value of stimuli from the environment, and it causes that those stimuli are becoming more and more wanted, although hedonic value or pleasurable properties of these stimuli may not increase or even develop tolerance (Robinson and Berridge, 2008).

When modeling sensitization, especially to pychostimulants such as MDPV, an effect that is observed and has been described repeatedly is the ability to induce the so-called psychomotor sensitization, this is, a gradual and persistent increase in locomotor stimulating effects such as locomotor activity or rotational movements or stereotyped behaviors (Robinson and Berridge, 2000).

There is one study that assessed the development and expression of behavioral sensitization to MDPV (Buenrostro-Jauregui et al., 2016) and it showed that 5 doses of $0.3 \mathrm{mg} / \mathrm{kg}$ are sufficient to induce a lasting locomotor sensitization as well as cross-sensitization with cocaine.

Self-administration studies have also been carried out with MDPV. Based on operant conditioning, developed by Skinner's work and according to which, if a response is contingently accompanied by the administration of a substance with reinforcing properties, the probability that the subject performs the response again will be increased (Skinner, 1938). Nevertheless, within this technique, changing certain conditions such as the number of responses to be performed by the subject to get a reinforce dose or the length of the training session various aspects of addiction, that will be discussed later, are modeled. Now we will focus on studies in 
which the reinforce is MDPV and requirements for obtaining dose are constant and low-demanding and self-administration sessions are relatively short, which are best suited to measure only the reinforcing effects of a substance. In this regard the work of Watterson et al. (2012) shows that the self-administration of MDPV was quickly achieved and in a similar manner to methamphetamine in rats. However, the work by Aarde et al. (2013) also compared the self-administration of methamphetamine and MDPV, and during the acquisition phase the number of drug infusions per hour was higher in the animals that received MDPV than those who received methamphetamine, but further analysis showed no statistical significant difference in the total amount of drug obtained for animals treated with either substance. More evidence in favor of the addictive potential of MDPV was revealed in the work by Aarde et al. in 2014, which showed that access to a reinforcing activity for the rats such as giving them access to a "running wheel" (Belke, 2004) did not reduce significantly the ratio self-administration of this substance in rats, while access to this device decreases self-administration behavior of other drugs (Cosgrove et al., 2002; McMillan et al., 1995; Miller et al., 2012).

The following kind of self-administration studies we mention are the so-called progressive ratio studies. In these studies requirements to obtain the dose of drug or reinforcer are increased, usually following an arithmetic progression or similar (Richardson and Roberts, 1996). However, if the interpretation of results focuses on the experimental subject, the breakpoints (requirement the animal fulfills to get the last dose of drug) can be interpreted as an index of motivation of the subject for getting the reinforcer (Deroche-Gamonet and Piazza, 2014). We found three studies that apply this technique using MDPV as the substance administered, but due to procedural differences is difficult to compare them with each other. Despite this, the work of Watterson et al. (2012) compared the results of various doses of methamphetamine with MDPV and looked at the dose both drugs shared $(0.05 \mathrm{mg} / \mathrm{kg} / \mathrm{inf})$ some breakpoints for MDPV were higher, although the difference was not significant. Another study (Aarde et al., 2013) compared breakpoints for different doses of MDPV and METH, and it showed that, for doses of 0.05 and $0.1 \mathrm{mg} / \mathrm{kg} / \mathrm{inf}$ rats produced significantly more responses on the drug-associated lever for MDPV than for METH.

\section{Conclusions}

The reviewed studies show that MDPV is a potent psychostimulant, which causes greater hyperlocomotion than cocaine and similar to METH. Additionally, it is able to set conditioned preferences within a wide range of doses, greater than those of amphetamine. Moreover, it has also been reported that it can induce behavioral sensitization with a very low dose, and selfadministration studies show its reinforcing properties. Interestingly, progressive ratio studies revealed that rats that self-administer MDPV also showed a great motivation for obtaining the drug, and additionally, wheel running access did not reduce MDPV self-administration rates. Taken together, these findings show that MDPV accomplishes all behavioral features that addictive psychostimulants do, but there are also some of findings like the low dose required to induce sensitization, how readily rats acquire MDPV self-administration behavior, the higher breaking points than those found with METH, and the lack of effect of running wheel access, that hint at a greater addictive potential. More studies, however, including models that accomplish several behavioral features reminiscent of the human addicts (Deroche-Gamonet and Piazza, 2014) would be useful in order to further enlighten the issue. 


\section{References}

Aarde, S. M., Huang, P. K., Creehan, K. M., Dickerson, T. J., Taffe, M. A. (2013). The novel recreational drug 3,4-methylenedioxypyrovalerone (MDPV) is a potent psychomotor stimulant: self-administration and locomotor activity in rats. Neuropharmacology, 71, 130140.

Aarde, S. M., Huang, P. K., Dickerson, T. J., Taffe, M. A. (2014). Binge-like acquisition of 3,4methylenedioxypyrovalerone (MDPV) self-administration and wheel activity in rats. Psychopharmacology (Berl), 232, 1867-1877.

Baumann, M. H., Partilla, J. S., Lehner, K. R., Thorndike, E. B., Hoffman, A. F., Holy, M., Rothman, R. B., Goldberg, S. R., Lupica, C. R., Sitte, H. H., Brandt, S. D., Tella, S. R., Cozzi, N. V, Schindler, C.W. (2013). Powerful cocaine-like actions of 3,4-methylenedioxypyrovalerone (MDPV), a principal constituent of psychoactive "bath salts" products. Neuropsychopharmacology, 38, 552-562.

Bardo, M. T., Bevins, R. A. (2000). Conditioned place preference: what does it add to our understanding of preclinical reward. Psychopharmacology, 153, 31-43.

Belke, T.W. (2004). Responding for sucrose and wheel-running reinforcement: effect of body weight manipulation. Behavioral Processes, 65, 189-199.

Braida, D., losuè, S., Pegorini, S., Sala, M. (2004). Delta9-tetrahydrocannabinol-induced conditioned place preference and intracerebroventricular self-administration in rats. European Journal of Pharmacology, 506, 63-69.

Buenrostro-Jáuregui, M. H., Ciudad-Roberts, A., Moreno, J., López-Arnau, R., Muñoz-Villegas, P., Pubill, D., Escubedo, E., Camarasa, J. (2016). Changes in creb and deltafosb are associated with the behavioural sensitization induced by MDPV. Journal of Psychopharmacology, 30, 707-712.

Carbo-Gas, M., Vazquez-Sanroman, D., Aguirre-Manzo, L., Coria-Avila, G. A., Manzo, J., Sanchis-Segura, C., Miquel, M. (2014). Involving the cerebellum in cocaine-induced memory: pattern of cFos expression in mice trained to acquire conditioned preference for cocaine. Addiction Biology, 19, 61-76.

Coppola, M., Mondola, R. (2012). 3,4-methylenedioxypyrovalerone (MDPV): chemistry, pharmacology and toxicology of a new designer drug of abuse marketed online. Toxicology Letters, 208, 12-15.

Cosgrove, K., Hunter, R., Carroll, M. (2002). Wheel-running attenuates intravenous cocaine self-administration in rats: sex differences. Pharmacology Biochemistry and Behavior, 73, 663-671.

Csák, R., Demetrovics, Z., Rácz, J. (2013). Transition to injecting 3,4-methylene-dioxy-pyrovalerone (MDPV) among needle exchange program participants in Hungary. Journal of Psychopharmacology, 27, 559-563.

De Felice, L. J., Glennon, R., Negus, S. S. (2014). Synthetic cathinones: chemical phylogeny, physiology, and neuropharmacology. Life Sciences, 97, 20-26.

Deniker, P., Loo, H., Cuche, H., Roux, J. M. (1975). Abuse of pyrovalerone by drug addicts. Annals of Medical Psychology, 2, 745-748.

Deroche-Gamonet, V., Piazza, P.V. (2014). Psychobiology of cocaine addiction: Contribution of a multi-symptomatic animal model of loss of control. Neuropharmacology, 76 , 437-449.

Fantegrossi, W. E., Gannon, B. M., Zimmerman, S. M., Rice, K. C. (2013). In vivo effects of abused "bath salt" constituent 3,4-methylenedioxypyrovalerone (MDPV) in mice: drug discrimination, thermoregulation, and locomotor activity. Neuropsychopharmacology, 38, 563-573. 
Goldberg, J., Gardos, G., Cole J. O. (1973). A controlled evaluation of pyrovalerone in chronically fatigued volunteers. International Pharmacopsychiatry, 8, 60-69.

Kalix, P. (1992). Cathinone, a natural amphetamine. Pharmacology and Toxicology. 70, 77-86.

Karlsson, L., Andersson, M., Kronstrand, R., Kugelberg, F. C. (2014). Mephedrone, methylone and 3,4-methylenedioxypyrovalerone (MDPV) induce conditioned place preference in mice. Basic and Clinical Pharmacology and Toxicology, 115, 411-416.

King, H. E., Wetzell, B., Rice, K. C., Riley, A. L., (2015). An assessment of MDPV-induced place preference in adult Sprague-Dawley rats. Drug and Alcohol Dependence, 146, 116-119.

Kolanos, R., Partilla, J. S., Baumann, M. H., Hutsell, B. A., Banks, M. L., Negus, S. S., Glennon, R. (2015). Stereoselective Actions of Methylenedioxypyrovalerone (MDPV) to Inhibit Dopamine and Norepinephrine Transporters and Facilitate Intracranial Self-Stimulation in Rats. ACS Chemical Neuroscience, 6, 771-777.

Kolanos, R., Solis, E. Jr., Sakloth, F., De Felice, L. J., Glennon, R. A. (2013). "Deconstruction" of the Abused Synthetic Cathinone Methylenedioxypyrovalerone (MDPV) and an Examination of Effects at the Human Dopamine Transporter. ACS Chemical Neuroscience, 1, 5-10.

Koob, G. F., Volkow, N. D. (2010). Neurocircuitry of addiction. Neuropsychopharmacology, 35, 217-238.

Marusich, J., Grant, K. R., Blough, B. E., Wiley, J. L. (2012). Effects of synthetic cathinones contained in "bath salts" on motor behavior and a functional observational battery in mice. Neurotoxicology, 33, 1305-1313.

Mead, A. N., Brown, G., Le Merrer J., Stephens, D. N. (2005). Effects of deletion of Gria1 or Gria2 genes encoding glutamatergic AMPA receptor subunits on place preference conditioning in mice. Psychopharmacology, 179, 164-171.

McMillan, D., McClure, G., Hardwick, W., (1995). Effects of access to a running wheel on food, water and ethanol intake in rats bred to accept ethanol. Drug and Alcohol Dependence, 40, 37-42.

Miller, M. L., Vaillancourt, B. D., Wright, M. J., Aarde, S. M., Vandewater, S. A., Creehan, K. M., Taffe, M. A. (2012). Reciprocal inhibitory effects of intravenous d-methamphetamine selfadministration and wheel activity in rats. Drug and Alcohol Dependence, 121, 90-96.

NIDA Media Guide (online) Bethesda (MD). Available from http://www.drugabuse.gov/, recovered on April 14 $4^{\text {th }}, 2014$.

Penders, T. M., Gestring, R., (2011). Hallucinatory delirium following use of MDPV: "Bath Salts". General and Hospital Psychiatry, 33, 525-526.

Richardson, N., Roberts, D. (1996). Progressive ratio schedules in drug self-administration studies in rats: a method to evaluate reinforcing efficacy. Journal of Neuroscience Methods, 66, 1-11.

Robinson, T., Berridge, K. (2000). The psychology and neurobiology of addiction: an incentivesensitization view. Addiction, 95, 91-117.

Robinson, T. E., Berridge, K. C. (2008). Review. The incentive sensitization theory of addiction: some current issues. Philosophic Transanctions of the Royal Society, Series B, Biological Sciences, 363, 3137-3146.

Sanchis-Segura, C., Spanagel, R. (2006). Behavioural assessment of drug reinforcement and addictive features in rodents: an overview. Addiction Biology, 11, 2-38.

Simonsen, K. W., Edvardsen, H. M. E., Thelander, G., Ojanperä, I., Thordardottir, S., Andersen, L. V., Kriikku, P., Vindenes, V., Christoffersen, D., Delaveris, G. J. M., Frost, J., (2015). Fatal poisoning in drug addicts in the Nordic countries in 2012. Forensic Science. International, 248C, 172-180. 
Skinner, B. F., (1938). The behavior of organisms. New York: Appleton-Century-Crofts

Smith, C., Cardile, A. P., Miller, M. (2011). Bath salts as a "legal high". American Journal of Medicine, 124, 7-8.

United Nations Office on Drugs and Crime (UNODC). World Drug Report 2013. UN Publication, NY, 2013.

Watterson, L. R., Kufahl, P. R., Nemirovsky, N. E., Sewalia, K., Grabenauer, M., Thomas, B. F., Marusich, J. A., Wegner, S., Olive, M. F. (2014). Potent rewarding and reinforcing effects of the synthetic cathinone 3,4-methylenedioxypyrovalerone (MDPV). Addiction Biology, 19, 165-174.

Wise, R. A., Bozarth, M. A. (1987). A psychomotor stimulant theory of addiction. Psychology Reviews, 94, 469-492.

Yohannan, J., Bozenko, J., Joseph, S. (2010). The characterization of 3, 4-methylenedioxypyrovalerone (MDPV). Microgram Journal, 7, 5-8. 